\title{
Atividade antioxidante in vitro e in vivo de café bebida mole
}

\author{
Sheila Andrade Abrahão(1), Rosemary Gualberto Fonseca Alvarenga Pereira(2), \\ Raimundo Vicente de Sousa(2) e Adriene Ribeiro Lima ${ }^{(2)}$
}

(1)Instituto Federal Fluminense, Campus Bom Jesus do Itabapoana, CEP 28360-000 Bom Jesus do Itabapoana, RJ.
E-mail: sheilanutri@yahoo.com.br (2)Universidade Federal de Lavras, Caixa Postal 3.037, CEP 37200-000 Lavras, MG.
E-mail: rosegfap@ufla.br, rvsousa@ufla.br, biodri@hotmail.com

Resumo - O objetivo deste trabalho foi determinar a atividade antioxidante do café, bebida mole, in vivo e in vitro, antes e após a torração. Para a análise da atividade antioxidante in vitro, foram utilizados os métodos de sequestro de radicais livres (DPPH) e de atividade quelante de íons $\mathrm{Fe}^{2+}$. Foram utilizados, para o ensaio in vivo, ratos Zucker diabéticos, portadores de síndrome metabólica, e ratos Zucker controle. Os animais receberam doses diárias das bebidas de café, por gavagem, por 30 dias. Após o tratamento, foi realizada a avaliação de peroxidação lipídica. As amostras torradas apresentaram a maior percentagem de sequestro de radicais livres. As concentrações nas amostras de café verde e torrado foram similares às do padrão Trolox. Das amostras torradas, a torração média se destacou com maior atividade quelante de íons $\mathrm{Fe}^{2+}$. Os cafés verdes mostraram maior poder quelante do que os torrados. Compostos presentes no extrato diminuíram a lipoperoxidação hepática e renal que é comum em casos de diabetes e síndrome metabólica. O café apresenta atividade antioxidante e protege o fígado e os rins dos animais contra a lipoperoxidação comumente presente em quadros de diabetes mellitus tipo 2 e síndrome metabólica.

Termos para indexação: Coffea arabica, diabetes mellitus tipo 2, peroxidação lipídica, radicais livres.

\section{In vitro and in vivo antioxidant activity of soft coffee}

\begin{abstract}
The objective of this work was to determine the in vivo and in vitro antioxidant activity of soft coffee beverages, before and after roasting. For the analysis of the antioxidant activity, the methods of free radical sequestration (DPPH) and of the chelating activity of $\mathrm{Fe}^{2+}$ ions were used. In vivo tests were performed with diabetic Zucker rats with metabolic syndrome and control Zucker rats. The animals received daily doses of coffee drinks by gavage for 30 days. After treatment, lipid peroxidation was evaluated. Roasted coffee samples had the highest percentage of free radical sequestration. Concentration in both green and roasted coffee samples was similar to that of the Trolox standard. From the roasted samples, medium roast stood out with greater $\mathrm{Fe}^{2+}$ ion chelating activity. Green coffees showed higher quelating power than the roasted ones. The compounds in the extract decreased the lipid peroxidation in the liver and kidney which is common in cases of diabetes and metabolic syndrome. Coffee has an antioxidant activity and protects the liver and kidneys of animals from lipid peroxidation commonly present in type 2 diabetes mellitus and metabolic syndrome.
\end{abstract}

Index terms: Coffea arabica, type 2 diabetes mellitus, lipid peroxidation, free radicals.

\section{Introdução}

O café é uma bebida de grande popularidade, com aroma e sabor característicos, consumida mundialmente. Muitas pesquisas têm demonstrado que os constituintes do café provocam várias respostas celulares e farmacológicas, num largo espectro de sistemas biológicos (Daglia et al., 2000; Natella et al., 2002; Duarte et al., 2005; Ozercan et al., 2006; Naidu et al., 2008). Há, entretanto, estudos epidemiológicos que contradizem os efeitos benéficos da ingestão de café (Tanaka et al., 1998). Algumas destas controvérsias dizem respeito ao aumento ou redução das oxidações biológicas (Somoza et al., 2003).

Os danos oxidativos induzidos nas células e tecidos têm sido relacionados à etiologia de várias doenças, inclusive as degenerativas como as cardiopatias, aterosclerose e problemas pulmonares. Os danos no DNA, causados pelos radicais livres, também desempenham um papel importante nos processos de mutagênese e carcinogênese (Poulsen et al., 1998).

O stress oxidativo, avaliado laboratorialmente por meio de índices de peroxidação lipídica, encontra-se aumentado no diabetes mellitus tipo 2, mesmo em 
doentes ainda sem graves complicações. Apesar dessa evidência de que o stress oxidativo pode contribuir para a manifestação e progressão das complicações diabéticas, resta ainda esclarecer se o estresse oxidativo está associado ou se é causa das modificações fisiopatológicas subjacentes à diabetes (Lemos et al., 2007).

Os antioxidantes são agentes responsáveis pela inibição e redução das lesões causadas pelos radicais livres nas células. De acordo com Sies \& Stahl (1995) antioxidante é qualquer substância que, presente em baixas concentrações em comparação à do substrato oxidável, atrasa ou inibe a oxidação deste substrato de maneira eficaz.

Segundo Duarte et al. (2005), cafés crus ou torrados podem agir como antioxidantes, in vitro e in vivo, além de inibir a peroxidação de lipídeos, e os compostos fenólicos são os responsáveis por esta ação.

Nascimento (2006) observou redução progressiva da atividade antioxidante com o aumento do grau de torração. $\mathrm{O}$ café submetido à torração moderadamente clara apresentou atividade antioxidante máxima, enquanto o café com maior grau de torração apresentou a menor atividade antioxidante. Assim, as torrações mais claras seriam mais benéficas à saúde humana e mais eficazes na proteção das células contra os efeitos oxidativos.

Daglia et al. (2000) analisaram a capacidade protetora do café contra a peroxidação de lipídios, em fígado de ratos, e observaram que as amostras apresentaram aumento na atividade protetora com a torração. Resultados semelhantes foram obtidos por Borreli et al. (2002), que observaram a redução da peroxidação do acido linoleico, em cultura de células, com o aumento da torração. Castillo et al. (2002), avaliaram a atividade antioxidante de café submetido a diferentes graus de torração. Apesar da diminuição do conteúdo de ácidos clorogênicos, a atividade antioxidante das melanoidinas dos cafés sob torração clara e média foi maior do que a do café in natura.

De acordo com Araújo (2007), durante o processo de torração, ocorre o rompimento das ligações entre os compostos fenólicos e as moléculas ligadas a eles, o que confere aos compostos resultantes uma estrutura com maior capacidade antioxidante.

Em contrapartida, alguns trabalhos indicam que a torração propicia a formação de acrilamida (ACM) que apresenta uma potencial atividade oxidante em humanos. Germano \& Germano (2002) relataram a presença de ACM em alguns alimentos, quando assados, fritos ou torrados, e os cereais, as batatas e o café são possivelmente suas maiores fontes de ingestão.

Apesar da discussão em torno da descoberta da ACM em alimentos, ainda há polêmica quanto aos riscos potenciais à saúde humana. Pesquisas apontam a acrilamida como neurotóxica ao ser humano, efeito conhecido há mais de trinta anos, em especial a partir da exposição ocupacional do indivíduo a essa substância. Embora os dados disponíveis sejam limitados, na análise de risco em induzir tumores na população humana, a ACM foi classificada como um provável carcinógeno humano (World Health Organization, 2002).

Assim, como muitos antioxidantes, o café pode exibir efeitos in vitro e in vivo duplos, altamente dependentes de parâmetros tais como a dose e a composição química dos grãos. Consequentemente, as propriedades pro- e antioxidantes dos alimentos e das bebidas devem ser interpretadas com cuidado, e os resultados não são facilmente extrapolados para avaliar o impacto na saúde humana (Stadler et al., 1994).

O objetivo deste trabalho foi avaliar a atividade antioxidante do café bebida mole, in vitro e in vivo, antes e após a torração.

\section{Material e Métodos}

Foram utilizadas amostras de café (Coffea arabica L.) provenientes da safra 2007/2008, do Município de Varginha, sul de Minas Gerais. As amostras foram torradas em torrador BRZ 6 Probat Leogap (Leogap Indústria e Comércio de Máquinas Ltda., Curitiba, PR, Brasil), com capacidade para $1 \mathrm{~kg}$, nos graus de torração claro, médio e escuro, classificados por meio do sistema colorimétrico MW-A Roast Color Classification (Agtron Inc., Reno, NV, EUA). Em seguida, os grãos torrados foram moídos em moedor elétrico Probat Leogap (Leogap Indústria e Comércio de Máquinas Ltda., Curitiba, PR, Brasil), em granulometria fina, empacotados em embalagens de polietileno/alumínio/ polipropileno, selados a vácuo e armazenados a $-20^{\circ} \mathrm{C}$, até o uso.

Os grãos crus foram moídos em granulometria fina, em moinho IKA A11 (Ika Works Inc., Arthur Nogueira, SP, Brasil), com auxílio de nitrogênio líquido.

Para a análise da atividade sequestrante de radicais livres 1,1-difenil-2-picril-hidrazil (DPPH) da bebida 
de café, cada amostra foi diluída em etanol a 25, 50, 100, $200 \mu \mathrm{g} \mathrm{mL}^{-1}$. A $4 \mathrm{~mL}$ da amostra adicionou-se $1 \mathrm{~mL}$ de DPPH $\left(0,5 \mathrm{mmol} \mathrm{L}^{-1}\right)$ igualmente diluído em etanol. A mistura foi acondicionada em tubo de ensaio âmbar e agitada. Após $30 \mathrm{~min}$, foi realizada a leitura a $517 \mathrm{~nm}$. A diminuição da absorbância indica a atividade sequestrante de radicais livres. Os testes foram realizados em triplicata. A atividade sequestrante de radicais livres (ASRL) foi expressa em percentagem, por comparação aos controles butil hidroxi tolueno (BHT), ácido ascórbico e Trolox, nas mesmas diluições das amostras de café, segundo a equação $\operatorname{ASRL}(\%)=[(\mathrm{Ac}-\mathrm{At}) / \mathrm{Ac}] \times 100$, em que: Ac é a absorbância controle, e At a absorbância teste (amostra).

A atividade quelante de íons $\mathrm{Fe}^{2+}$ foi realizada de acordo com a metodologia descrita por Tang et al. (2002), com modificações. Cada amostra foi diluída em etanol a 200, 400, 800, $1.600 \mu \mathrm{g} \mathrm{mL}^{-1}$. Uma alíquota de $1 \mathrm{~mL}$ das amostras das bebidas de café verde, em torração clara, média e escura foi transferida para tubos de ensaio âmbar de $25 \mathrm{~mL}$. A esta alíquota foram adicionados: $3,7 \mathrm{~mL}$ de água deionizada; $0,1 \mathrm{~mL}$ de $\mathrm{FeSO}_{4} 2 \mu \mathrm{mol} \mathrm{mL}-1$; e $0,2 \mathrm{~mL}$ de ferrozina $5 \mu \mathrm{mol} \mathrm{mL}^{-1}$ [3-(2-piridil)-5,6-bis-(4-ácido fenil sulfônico)-1,2,4-triazina]. O padrão, neste teste, foi feito pela substituição de $1 \mathrm{~mL}$ da amostra por água deionizada. A mistura foi agitada e, após $20 \mathrm{~min}$, foi feita a leitura a $562 \mathrm{~nm}$, tendo-se ajustado o aparelho com o branco; neste caso, substitui-se a amostra por EDTA a $2 \%$. A redução da absorbância indica atividade quelante de $\mathrm{Fe}^{2+}$ que pode ser medida por AQ $(\%)=100-[(\mathrm{Ap}-\mathrm{At}) / \mathrm{Ap}] \times 100$, em que: AQ é a atividade quelante de $\mathrm{Fe}^{2+}$; Ap é a absorbância do padrão, que não foi incubado com o café; e At é a absorbância teste (amostras).

Para a determinação do efeito antioxidante in vivo do café, foram utilizados dez ratos Zucker fa/fa (recessivos com diabetes mellitus tipo 2) e 10 ratos Zucker fa/ + ou $+/+$ (dominantes, controle negativo, sem diabetes) machos, com oito semanas de idade, provenientes do Centro de Desenvolvimento de Modelos Experimentais, da Universidade Federal de São Paulo, São Paulo, SP. Os animais permaneceram durante todo o período experimental à temperatura de $23^{\circ} \mathrm{C}$, com período claro-escuro de 12 horas, e receberam ração comercial e água à vontade, em gaiolas metabólicas metálicas individuais, sem cama.
O experimento in vivo foi realizado no Biotério e Laboratório de Fisiologia e Farmacologia, do Departamento de Medicina Veterinária, da Universidade Federal de Lavras, Lavras, MG, com a devida aprovação do comitê de ética da própria instituição, pelo parecer n⿳o 015/2009.

Os animais foram divididos em quatro grupos e distribuídos em 20 gaiolas (um animal por gaiola, cinco animais por grupo), marcados individualmente $\mathrm{e}$ tratados de acordo com o protocolo a seguir: controle normal, sem diabetes mellitus tipo 2- - ratos Zucker $\mathrm{fa} /+$ ou $+/+$, alimentados por gavagem com água por 30 dias; normal tratado, sem diabetes mellitus tipo 2 ratos Zucker fa/+ ou +/+, alimentados com café torração média $\left(3,6 \mathrm{~mL} \mathrm{~kg}^{-1}\right.$ por dia), administrado por gavagem durante 30 dias; controle diabético, com diabetes mellitus tipo 2 - ratos Zucker fa/fa, alimentados por gavagem com água por 30 dias; diabético tratado, com diabetes mellitus tipo 2 - ratos Zucker fa/fa, alimentados com café torração média $\left(3,6 \mathrm{~mL} \mathrm{~kg}^{-1}\right.$ por dia), administrado por gavagem durante 30 dias.

O café recém-preparado foi administrado aos animais por gavagem oral, uma vez ao dia, por 30 dias, assim como a água do controle. A dose utilizada foi de $3,6 \mathrm{~mL} \mathrm{~kg}^{-1}$ por dia, correspondente ao consumo humano de cinco xícaras de $50 \mathrm{~mL}$ de café.

Decorrido o tempo, os animais foram anestesiados, por via intraperitoneal, com $35 \mathrm{mg} \mathrm{kg}^{-1}$ de tiopental, submetidos à ex-sanguinação por punção cardíaca e retirada dos rins e fígado. Os órgãos, após pesados, foram congelados em nitrogênio líquido e armazenados a $-80^{\circ} \mathrm{C}$.

A fim de determinar se a bebida de café é capaz de reduzir o estresse oxidativo, foi analisada a peroxidação de lipídeos isolados nos rins e fígados dos animais. A peroxidação de lipídeos foi determinada pela formação de substâncias reativas com ácido tiobarbitúrico (TBARS), de acordo com Winterbourn et al. (1985). Os produtos da peroxidação de lipídeos reagem com o ácido tiobarbitúrico e produzem um composto que apresenta absorbância a $532 \mathrm{~nm}$.

Os rins e os fígados dos animais foram pesados e homogeneizados em homogeneizador de tecidos, em banho de gelo, após adição de PBS $0,1 \mathrm{~mol} \mathrm{~L}^{-1}, \mathrm{pH} 7,4$ (volume equivalente a quatro vezes o peso de tecido fresco). $\mathrm{O}$ homogeneizado foi centrifugado a $3.000 \mathrm{~g}$ por $10 \mathrm{~min}$ a $4^{\circ} \mathrm{C}$, e o sobrenadante foi mantido em 
banho de gelo e utilizado nos ensaios para análise da peroxidação lipídica.

Alíquotas de $500 \mu \mathrm{L} \mathrm{L}^{-1}$ do sobrenadante foram misturadas a $500 \mu \mathrm{L} \mathrm{L}^{-1}$ de ácido clorídrico a $25 \%\left(\mathrm{v} \mathrm{v}^{-1}\right)$, $500 \mu \mathrm{L} \mathrm{L}^{-1}$ de ácido tiobarbitúrico a $1 \%\left(\mathrm{p} \mathrm{v}^{-1}, \mathrm{em} \mathrm{NaOH}\right.$ $\left.0,05 \mathrm{~mol} \mathrm{~L}^{-1}\right)$, e $45 \mu \mathrm{LL}^{-1}$ de BHT a $2 \%$ ( $\mathrm{p} \mathrm{v}^{-1}$, em etanol). A mistura foi aquecida em banho de água fervente durante $10 \mathrm{~min}$. Após o resfriamento em banho de gelo por $10 \mathrm{~min}$, foram adicionados $1,5 \mathrm{~mL}$ de butanol, e as amostras foram agitadas vigorosamente em vórtex. A seguir, foram centrifugadas a $900 \mathrm{~g}$, por 5 min, e a fração que continha butanol foi recolhida e utilizada para a determinação da absorbância a $532 \mathrm{~nm}$. A concentração de TBARS foi calculada a partir da curva-padrão de dialdeído malônico (MDA; $1,1,3,3$ tetraetoxipropano). Os resultados foram expressos em nanomoles por grama de MDA.

Utilizou-se o delineamento experimental inteiramente casualizado, com parcelas subdivididas. As análises antioxidantes in vitro compreenderam quatro concentrações, quatro níveis de torração (cru, claro, médio e escuro) e três repetições. Para as análises in vivo, foram utilizados dois tipos de bebida (água e café), duas linhagens de animais (Zucker fa/fa e Zucker fa/+ ou $+/+$ ) e cinco repetições para cada tratamento.

Os dados foram submetidos à análise de variância (ANOVA) e comparados pelo teste de Tukey, a $5 \%$ de probabilidade. Na análise da influência da concentração das bebidas de café sobre a atividade sequestrante de DPPH e a atividade quelante de metais, foi utilizado o teste de regressão.

\section{Resultados e Discussão}

O ácido ascórbico destacou-se com a maior atividade sequestrante de DPPH em todas as concentrações (Tabela 1). Entre as amostras de café analisadas, as torradas apresentaram a maior percentagem de sequestro de radicais livres e chegaram a $59,13 \%$ de atividade na concentração máxima testada (200 $\left.\mathrm{mg} \mathrm{L}^{-1}\right)$ na torração média. As concentrações apresentadas pelas amostras de café, tanto verdes quanto torradas, foram similares à do padrão Trolox, um análogo da vitamina $\mathrm{E}$.

A atividade sequestrante de radicais DPPH foi dependente da dose em todas as amostras avaliadas e no padrão BHT, ou seja, quanto maior a concentração das amostras maior a atividade antioxidante. Este fato não foi apresentado apenas pelo padrão ácido ascórbico.

A atividade sequestrante de radicais livres dos cafés verdes foi menor do que a apresentada por Naidu et al. (2008), que encontraram valores próximos a $80 \%$ em cafés verdes de C. arabica. Duarte et al. (2005) e Araújo (2007) utilizaram a mesma metodologia, para avaliar a atividade sequestrante de radicais livres de amostras de cafés torrados, e obtiveram valores na faixa de 82 a $92,52 \%$, para a concentração de $200 \mathrm{mg} \mathrm{L}^{-1}$, valores superiores aos obtidos neste trabalho.

Nas concentrações 25, 50, 100 e $200 \mathrm{mg} \mathrm{L}^{-1}$, a atividade sequestrante de radicais livres foi significativamente superior nas amostras obtidas a partir dos grãos torrados, em comparação à atividade nos extratos dos grãos in natura, tendo-se destacado os de torração média (Tabela 1). Stalmach et al. (2006) também verificaram que a capacidade antioxidante da bebida, preparada com grãos submetidos à torração média, foi o dobro daquela dos grãos verdes.

A potencialização da atividade antioxidante com a torração também foi observada por Nicoli et al. (1997) e Daglia et al. (2000), o que indica que outros compostos, que não os fenólicos, poderiam ser responsáveis pela atividade antioxidante em grãos torrados de café.

Segundo Araújo (2007), apesar da torração reduzir o conteúdo de polifenóis que, como visto anteriormente, apresentam comprovada ação antioxidante, os produtos da reação de Maillard, especialmente as melanoidinas, também apresentam ação antioxidante. Além disso, durante o processo de torração, as condições de tempo e temperatura podem romper as ligações entre os compostos fenólicos e as moléculas a eles ligadas, o

Tabela 1. Análise da atividade sequestrante de radicais DPPH (\%), em extratos obtidos de grãos de café antes e após três graus de torração, em quatro concentrações ${ }^{(1)}$.

\begin{tabular}{lcccc}
\hline Tratamento & \multicolumn{4}{c}{ Concentração $\left(\mathrm{mg} \mathrm{L}^{-1}\right)$} \\
\cline { 2 - 5 } & 25 & 50 & 100 & 200 \\
\hline Verde & $44,12 \mathrm{eB}$ & $44,89 \mathrm{eB}$ & $44,76 \mathrm{fB}$ & $51,57 \mathrm{eA}$ \\
Torração clara & $41,72 \mathrm{fB}$ & $49,49 \mathrm{dA}$ & $53,44 \mathrm{dA}$ & $55,30 \mathrm{dA}$ \\
Torração média & $54,45 \mathrm{cB}$ & $55,36 \mathrm{cB}$ & $58,48 \mathrm{cA}$ & $59,13 \mathrm{cA}$ \\
Torração escura & $46,92 \mathrm{~dB}$ & $48,22 \mathrm{~dB}$ & $48,35 \mathrm{eB}$ & $53,81 \mathrm{dA}$ \\
Butil hidroxi tolueno & $65,83 \mathrm{bC}$ & $70,70 \mathrm{bB}$ & $73,44 \mathrm{bB}$ & $77,18 \mathrm{bA}$ \\
Ácido ascórbico & $91,96 \mathrm{aA}$ & $92,46 \mathrm{aA}$ & $93,44 \mathrm{aA}$ & $92,21 \mathrm{aA}$ \\
Trolox & - & - & $46,42 \mathrm{f}$ & - \\
\hline
\end{tabular}

(1)Médias seguidas de letras iguais, minúsculas nas colunas e maiúsculas nas linhas, não diferem entre si, pelo teste de Tukey, a 5\% de probabilidade. 
que confere aos compostos resultantes uma estrutura com maior capacidade antioxidante.

A relação entre o grau de torração do café e a capacidade antioxidante varia de acordo com a espécie de café (arábica ou robusta), condições da torração, procedimento utilizado para extração e teste de antioxidação (Garambone \& Rosa, 2007).

Assim como no teste anterior, houve influência da torração sobre o poder quelante das amostras $(p<0,05)$. Entre as amostras torradas, a torração média se destacou com maior atividade quelante de íons $\mathrm{Fe}^{2+}$ (Tabela 2).

Pela regressão, verificou-se que todas as amostras apresentaram poder quelante de metais dependente da dose, que atingiu o seu máximo com a amostra verde que apresentou 55,40\% de atividade quelante. Os cafés verdes mostraram maior atividade antioxidante do que os torrados, diferentemente da atividade sequestrante de radicais livres, em que a maior concentração de polifenóis é favorável, pois um dos seus mecanismos de ação antioxidante de especial relevância é a capacidade de se ligar a metais como íons de ferro e cobre. Esses resultados estão de acordo com os de Santos et al. (2007), que encontraram maior atividade quelante nas amostras de café verde, provavelmente em razão da presença de compostos fenólicos funcionais.

Assim, conforme os dois testes de antioxidantes realizados, a bebida de café pode ser considerada como antioxidante; no entanto, sua ingestão pode contribuir para a quelação de metais de transição, o que pode levar à peroxidação lipídica, com consequente lesão às membranas plasmáticas e à oxidação do DNA, causando injúria ou morte celular (Halliwell \& Gutteridge, 1999).

A atividade antioxidante das amostras analisadas variou conforme a metodologia utilizada, o que mostra

Tabela 2. Atividade quelante de íons $\mathrm{Fe}^{2+}(\%)$, em extratos de grãos de café obtidos antes (verde) e após três graus de torração, em quatro concentrações ${ }^{(1)}$.

\begin{tabular}{lrrrrlll}
\hline Torração & \multicolumn{4}{c}{ Concentração $\left(\mathrm{mg} \mathrm{L}^{-1}\right)$} & Regressão & $\mathrm{R}^{2}$ \\
\cline { 2 - 5 } & \multicolumn{1}{c}{200} & \multicolumn{1}{c}{400} & \multicolumn{1}{c}{800} & 1.600 & & \\
\hline Verde & $10,3 \mathrm{aD}$ & $22,7 \mathrm{aC}$ & $32,0 \mathrm{aB}$ & $55,4 \mathrm{aA}$ & $\mathrm{y}=0,0305 \mathrm{x}+7,2578$ & 0,98 \\
Clara & $1,9 \mathrm{cD}$ & $3,8 \mathrm{cC}$ & $4,4 \mathrm{~dB}$ & $14,0 \mathrm{dA}$ & $\mathrm{y}=0,0085 \mathrm{x}-0,3061$ & 0,94 \\
Média & $4,4 \mathrm{bD}$ & $6,0 \mathrm{bC}$ & $9,6 \mathrm{bB}$ & $20,1 \mathrm{bA}$ & $\mathrm{y}=0,0097 \mathrm{x}-0,1452$ & 0,97 \\
Escura & $1,4 \mathrm{dD}$ & $3,1 \mathrm{dC}$ & $9,2 \mathrm{cB}$ & $14,7 \mathrm{cA}$ & $\mathrm{y}=0,0113 \mathrm{x}+1,5257$ & 0,99 \\
\hline
\end{tabular}

${ }^{(1)}$ Médias seguidas de letras iguais, minúsculas nas colunas e maiúsculas nas linhas, não diferem entre si, pelo teste de Tukey, a $5 \%$ de probabilidade. $\mathrm{CV}=0,09 \%$. a importância da realização de mais de uma análise para dar maior confiabilidade aos resultados.

Os índices de peroxidação lipídica no tecido hepático e renal dos animais estão apresentados na Tabela 3.

Durante a hiperglicemia persistente da diabetes, somada a outros fatores da síndrome metabólica como a obesidade, ocorre aumento da produção de radicais livres de oxigênio, por meio da auto-oxidação da glicose. Esses radicais exercem seus efeitos citotóxicos nos fosfolipídeos de membrana, o que resulta na formação de malonaldeído (MDA), um produto final da peroxidação lipídica que reage com o ácido tiobarbitúrico.

O consumo, durante 30 dias, de café torrado bebida mole foi efetivo na redução da produção de TBARS no fígado de ratos, o que indica que esta bebida confere proteção à membrana celular contra o ataque oxidativo. No tecido renal, apesar dos níveis de TBARS menores nos animais controle, esta diferença não foi significativa.

O estudo do café in vivo confirmou os resultados obtidos in vitro, ao mostrar significativa atividade antioxidante que protegeu o fígado dos animais contra a lipoperoxidação.

Os resultados encontrados corroboram os apresentados por Ozercan et al. (2006). Estes autores avaliaram o efeito antioxidante do café instantâneo em ratos e verificaram que o tratamento com café instantâneo reduziu significativamente os níveis de TBARS no tecido hepático dos animais.

Tabela 3. Teor de substâncias reativas ao ácido tiobarbitúrico (nmol mg ${ }^{-1}$ de MDA) em fígados e rins de $\operatorname{ratos}^{(1)}$.

\begin{tabular}{lcc}
\hline Tratamento $^{(2)}$ & \multicolumn{2}{c}{ Órgão } \\
\cline { 2 - 3 } & Rim & Fígado \\
\hline Controle normal & $0,47 \pm 0,18 \mathrm{ab}$ & $0,53 \pm 0,11 \mathrm{c}$ \\
Normal tratado & $0,45 \pm 0,03 \mathrm{~b}$ & $0,47 \pm 0,05 \mathrm{c}$ \\
Controle diabético & $0,63 \pm 0,18 \mathrm{a}$ & $1,12 \pm 0,22 \mathrm{a}$ \\
Diabético tratado & $0,47 \pm 0,04 \mathrm{ab}$ & $0,83 \pm 0,05 \mathrm{~b}$ \\
\hline Média & 0,50 & 0,71 \\
\hline
\end{tabular}

${ }^{(1)}$ Médias seguidas de letras iguais, nas colunas, não diferem entre si, pelo teste de Tukey, a 5\% de probabilidade. ${ }^{(2)}$ Controle normal, sem diabetes mellitus tipo 2 - ratos Zucker fa/+ ou $+/+$, alimentados por gavagem com água por 30 dias; normal tratado, sem diabetes mellitus tipo 2 - ratos $\mathrm{Zu}$ cker fa/+ ou +/+, alimentados com café torração média $\left(3,6 \mathrm{~mL} \mathrm{~kg}^{-1}\right.$ por dia), administrado por gavagem durante 30 dias; controle diabético, com diabetes mellitus tipo 2 - ratos Zucker fa/fa, alimentados por gavagem com água por 30 dias; diabético tratado, com diabetes mellitus tipo 2 - ratos Zucker fa/fa, alimentados com café torração média $\left(3,6 \mathrm{~mL} \mathrm{~kg}^{-1}\right.$ por dia), administrado por gavagem durante 30 dias. 
De acordo com Natella et al. (2002) e Fujioka \& Shibamoto (2006), os ácidos clorogênicos presentes na bebida de café podem ser absorvidos e exercem sua atividade antioxidante nos tecidos animais, assim como os produtos da reação de Maillard. Assim, a redução dos níveis de TBARS, observadas no fígado dos animais que receberam doses de café, no presente trabalho, pode ser atribuída à presença de ácidos clorogênicos e melanoidinas no extrato aquoso do café administrado.

Embora vários estudos citem a melanoidina e outros produtos da reação de Maillard como prováveis antioxidantes, há pesquisas que relatam uma propriedade oxidante dos produtos avançados da reação de Maillard (AGE) capazes de favorecer o surgimento e a progressão das diversas complicações do diabetes (Lemos et al., 2007). Por meio da geração de radicais livres, da formação de ligações cruzadas com proteínas ou de interações com receptores celulares, os AGE promovem, respectivamente, estresse oxidativo, alterações morfofuncionais e aumento da expressão de mediadores inflamatórios (Barbosa et al., 2008). Provavelmente, no tecido renal, o efeito antioxidante da bebida do café contrabalanceou o efeito oxidante dos produtos da reação de Maillard, e não houve diferença entre o grupo diabético tratado e o controle.

Os processos de absorção e utilização dos compostos antioxidantes presentes no café ainda não estão bem compreendidos. Porém, os resultados do presente trabalho indicam que há potenciais efeitos benéficos do café para a saúde, que contribuem para prevenir ou adiar o início de doenças degenerativas, em razão da combinação do teor de antioxidantes, por dose servida, com a frequência do consumo da bebida.

\section{Conclusões}

1. O café bebida mole apresenta atividade antioxidante in vitro.

2. A atividade sequestrante de radicais livres é intensificada com a torração dos grãos de café, e a atividade quelante de metais é superior nos grãos in natura.

3. O café apresenta atividade antioxidante, pois protege o fígado e os rins dos animais contra a lipoperoxidação comumente presente em quadros de diabetes mellitus tipo 2 e síndrome metabólica.

\section{Agradecimentos}

Ao Conselho Nacional de Desenvolvimento Científico e Tecnológico, por concessão de bolsa.

\section{Referências}

ARAÚJO, F.A. Café (Coffea arabica, L.) submetido a diferentes condições de torrefação: caracterização química e avaliação da atividade antioxidante e sensorial. 2007. 130p. Tese (Doutorado) Universidade de São Paulo, São Paulo.

BARBOSA, J.H.P.; OLIVEIRA, S.L.; SEARA, L.T. O papel dos produtos finais da glicação avançada (AGEs) no desencadeamento das complicações vasculares do diabetes. Arquivo Brasileiro de Endocrinologia e Metabolismo, v.52, p.940-950, 2008.

BORRELLI, R.C.; VISCONTI, A.; MENNELlA, C.; ANESE, M.; FOGLIANO, V.; Chemical characterization and antioxidant properties of coffee melanoidins. Journal of Agricultural and Food Chemistry, v.50, p.6527-6533, 2002.

CASTILLO, M.D. del; AMES, J.M.; GORDON, M.H. Effect of roasting on the antioxidant activity of coffee brew. Journal of Agriculture and Food Chemistry, v.50, p.3698-3703, 2002.

DAGLIA, M.; PAPETTI, A.; GREGOTTI, C.; BERTÈ, F.; GAZZANI, G. In vitro antioxidant and ex vivo protective activities of green and roasted coffee. Journal of Agricultural and Food Chemistry, v.48, p.1449-1454, 2000.

DUARTE, S.M. da S.; ABREU, C.M.P. de; MENEZES, H.C.; SANTOS, M.H. dos; GOUVÊA, C.M.P. Effect of processing and roasting of the antioxidant activity of coffee brews. Ciência e Tecnologia de Alimentos, v.25, p.387-393, 2005.

FUJIOKA, K.; SHIBAMOTO, T. Quantitation of volatiles and nonvolatiles acids in an extract from coffee beverages: correlation with antioxidant activity. Journal of Agricultural and Food Chemistry, v.54, p.6054-6058, 2006.

GARAMBONE, E.; ROSA, G. Possíveis benefícios do ácido clorogênico à saúde. Alimentos e Nutrição, v.18, p.229-235, 2007.

GERMANO, P.M.L.; GERMANO, M.I.S. Acrilamida: nova ameaça à segurança alimentar? Higiene Alimentar, v.16, p.37-41, 2002.

HALLIWELL, B.; GUTTERIDGE, J.M.C. Free radicals in biology and medicine. $3^{\text {rd }}$ ed. New York: Oxford University, 1999. 936p.

LEMOS, E.T. de; REIS, F.; BAPTISTA, S.; GARRIDO, A.P.; PINTO, R.; SEPODES, B.; VALA, H.; ROCHA-PEREIRA, P.; SILVA, A.S.; TEIXEIRA, F. Efeitos do exercício físico aeróbio no perfil metabólico e oxidativo de ratos diabéticos tipo 2. Boletim da Sociedade Portuguesa de Hemorreologia e Microcirculação, v.22, p.168-174, 2007.

NAIDU, M.M.; SULOCHANAMMA, G.; SAMPATHU, S.R.; SRINIVAS, P. Studies on extraction and antioxidant potential of green coffee. Food Chemistry, v.107, p.377-384, 2008.

NASCIMENTO, P.M. do. Estudo da composição química, atividade antioxidante e potencial odorífico de um café Conillon, 
em diferentes graus de torrefação e análise comparativa com café arábica. 2006. 90p. Dissertação (Mestrado) - Universidade Federal de Uberlândia, Uberlândia.

NATELLA, F.; NARDINI, M.; GIANNETTI, I.; DATTILO, C.;SCACCINI, C. Coffee drinking influences plasma antioxidant capacity in humans. Journal of Agricultural and Food Chemistry, v.50, p.6211-6216, 2002.

NICOLI, M.C.; ANESE, M.; MANZOCCO, L.; LERICE, C.R. Antioxidant properties of coffee brews in relation to the roasting degree. Food Science and Technology, v.30, p.292-297, 1997.

OZERCAN, I.H.; DAGLI, A.F.; USTUNDAG, B.; OZERCAN, M.R.; BAHCECIOGLU, I.H.; CELIKD, H.; YALNIZ, M.; POYRAZOGLU, O.K.; ATASEVEN, H. Does instant coffee prevent acute liver injury induced by carbon tetrachloride (CCl4)? Hepatology Research, v.35, p.163-168, 2006.

POULSEN, H.E.; PRIEME, H.; LOFT, S. Role of oxidative DNA damage in cancer initiation and promotion. European Journal of Cancer Prevention, v.7, p.9-16, 1998.

SANTOS, M.H. dos; BATISTA, B.L.; DUARTE, S.M. da S.; ABREU, C.M.P. de; GOUVÊA, C.M.C.P. Influência do processamento e da torrefação sobre a atividade antioxidante do café (Coffea arabica). Química Nova, v.30, p.604-610, 2007.

SIES, H.; STAHL, W. Vitamins E and C, beta-carotene, and other carotenoids as antioxidants. American Journal of Clinical Nutrition, v.62, p.1315-1321, 1995.

SOMOSA, V.; LINDENMEIER, M.; WENZEL, E.; FRANK, O.; ERBERSDOBLER, H.F.; HOFMANN, T. Activity-guided identification of a chemopreventive compound in coffee beverage using in vitro and in vivo techniques. Journal of Agricultural and Food Chemistry, v.51, p.6861-6869, 2003.

STADLER, R.H.; TURESKY, R.J.; MULLER, O.; MARKOVIC, J.; LEONG-MORGENTHALER, P.M. The inhibitory effects of coffee on radical-mediated oxidation and mutagenicity. Mutation Research, v.308, p.177-190, 1994.

STALMACH, A.; MULlEN, W.; NAGAI, C.; CROZIER, A. On-line HPLC analysis of the antioxidant activity of phenolic compounds in brewed, paper-filtered coffee. Brazilian Journal of Plant Physiology, v.18, p.253-262, 2006.

TANAKA, K.; TOKUNAGA, S.; KONO, S.; TOKUDOME, S.; AKAMATSU, T.; MORYAMA, T.; ZAKOUJI, H. Coffee consumption and decreased serum gamma-glutamyltransferase and aminotransferase activities among male alcohol drinkers. International Journal of Epidemiology, v.27, p.438-443, 1998.

TANG, S.Z.; KERRY, J.P.; SHEEHAN, D.; BUCKLEY, D.J. Antioxidative mechanisms of tea catechins in chicken meat systems. Food Chemistry, v.76, p.45-51, 2002.

WINTERBOURN, C.C.; GUTTERIDGE, J.M.; HALLIWELL, B. Doxorubicin-dependent lipid peroxidation at low partial pressures of $\mathrm{O}_{2}$. Journal of Free Radicals Biology and Medicine, v.1, p.43-49, 1985.

WORLD HEALTH ORGANIZATION. FAO/WHO consultation on the health implications of acrylamide in food, Geneva, 25-27 June 2002: sumary report. Geneva: WHO, 2002. 12p.

Recebido em 12 de setembro de 2011 e aprovado em 14 de dezembro de 2011 